\title{
Interpretations of Chinese Paintings
}

\author{
Wei Shu ${ }^{1}$ \\ ${ }^{1}$ Beijing Information Science and Technology University, Beijing, China \\ Correspondence: Wei Shu, School of Foreign Studies, Beijing Information Science and Technology University, \\ Beijing, China. E-mail: susiejournal@163.com
}

Received: March 4, 2014 Accepted: March 24, $2014 \quad$ Online Published: April 13, 2014

doi:10.5430/wjss.v1n2p43 URL: http://dx.doi.org/10.5430/wjss.v1n2p43

\begin{abstract}
Cultivated in Chinese history, literature and philosophy, Chinese painting is unique in its motifs, forms and techniques. This paper studies firstly the materials and tools employed in Chinese Painting; secondly it comes to the discussion of the uniqueness of Chinese Painting in different aspects and some strategies are given to viewers to better comprehend Chinese Painting; thirdly this paper demonstrates how to "read" Chinese Paintings through the detailed analysis of some works; and finally the paper comes to the conclusions that Chinese Painting is the treasure of China's culture. To better understand the essence of Chinese Paintings, the works have to be fully considered in the cultural and social context.
\end{abstract}

Keywords: Chinese Painting, uniqueness, cultural and social context, interpretation

\section{Introduction}

Painting was practiced in China from very early times and in a variety of media, which can be illustrated in both textual and archaeological sources. It's hard to trace the exact origin of Chinese Painting, but according to literatures passed down, wall paintings appeared first in great numbers in China's history, but because so little early architecture in China remained complete over the centuries, few of these large-scale paintings have survived. Paintings were also often done on screens, which served in a sense as portable walls, but these too have not survived. From the Song dynasty onwards, paintings, in other forms, such as the hanging scroll and the hand scroll, were collected and passed on to later generations in significant quantities. These paintings offer vivid and detailed description of everyday life and social customs, which is unavailable from written texts. By looking into them, historians can imagine what life looked like in earlier periods. Furthermore, because paintings of this period have come to be viewed as one of the highest cultural achievements in China's history, they provide valuable insight into aesthetic values and tastes that would have lasting impact on later artists and connoisseurs.

\section{Chinese Painting - Tools and Materials}

As China's unique art style, traditional Chinese painting has its special materials and tools, consisting of brushes of different types, ink and pigments of different textures, rice paper (Xuan paper), silk and various kinds of inkstones. Basically four essential elements: the brush, ink, paper, and the ink stone are called "The Four Treasures of the Study" ever since ancient times.

A man named Meng Tien is said to have invented the brush. He lived about 4000 years ago and may have gotten the idea from people who lived before that. There are three types of brushes used in traditional Chinese painting: soft, stiff, and mixed. Sometimes two very different hair types are used together, giving the artist the opportunity to create different marks and to experiment with ink loading. The soft brush absorbs a large amount of water and is suitable for painting flowers and leaves and applying water and colors. The stiff brush is used to give the effect of strength, elasticity and resilience. The mixed brush is used for the combined effect of strength and grace and therefore can be used for painting flowers and leaves.

The ink used for painting is made by grinding an ink stick on an inkstone. There are also prepared ink in bottles. Ink 
sticks are often beautifully decorated and many are collected purely for their appearance. Different colors may vary-blue-black, brown-black and a true black, depending on the part of the pine tree that has been used to make the ink sticks.

Pigments are used in addition to ink for coloring in Chinese painting. Chinese paintings are often carried out solely in shades of black giving a monochrome effect. In landscapes and some early styles the color was used very lightly and sparingly, with the ink giving the structure of the painting. Pigments for Chinese painting are classified as transparent or opaque. Transparent colors are made with plant pigments while opaque colors (also called mineral colors) are made mainly of minerals.

Rice paper (Xuan paper) is the special material for traditional Chinese painting. It is so called because it is produced at Xuancheng in Jing County, Anhui Province. Basically, Xuan paper may be divided into processed or unprocessed. Unprocessed Xuan paper absorbs moisture and ink, and colors sink in easily when water is added while processed paper does not let ink and colors sink in. This kind of paper is suitable for doing paintings in the meticulous style. Sometimes Chinese artists also paint on silk fabric. In general, it is used after being treated and is used mostly for paintings in the meticulous style. Raw silk is used for freehand painting.

The inkstone is the tool for grinding the ink stick. A good inkstone is a beautiful handicraft and it serves as the tool to grind the ink fine, even and thick, and protects the ink from drying quickly.

Besides, there are some other tools widely used in Chinese Paintings, such as color-mixing tray and brush wash utensil. Color-mixing tray is a dish or plate for mixing colors. With its mouth wide open, brush wash utensil is the equipment for washing brushes.

\section{The Uniqueness of Chinese Painting}

Cultivated in Chinese history, literature and philosophy, Chinese painting is different from that of the West in its motifs, forms and techniques. It's a complicated combination of poetry, calligraphy, painting and seals. Many of the painters were multi-talented poets and calligraphers.

\subsection{The Uniqueness of Chinese Painting in Techniques}

What makes Chinese painting different from the western painting in visual effect lies firstly in the brush pens the Chinese painters use. Either soft or stiff, the brushes can run freely on the rice paper and tell the viewers what the painters are trying to present. Chinese paintings present the ideas and motifs in lines and dots while their western counterparts employ colors, proportion and perspective.

Chinese paintings are usually presented in scrolls and do not abide by the so-called "Golden Law" - the Western notion of the Law of Proportionality. This law states that two unequal parts of a whole must be in relationship to each other to create a balanced image to the eye. Instead of the "focus perspective" used in Western paintings, Chinese paintings use "spread-point perspective," which offers a delicate sense of proportion. This unique feature puzzles a lot of western viewers, who find they are having a hard time trying to figure out the proportions and relationship of the subjects shown on the paper. Sometimes the mountains far away are standing in line with the huts nearby while the giant stone is just the same size of the little flower leaning towards it. This difference may be traced back to the origins of history and religion. In the western world, the earliest painters were supposed to serve the religious purpose. They have to describe the human beings in an accurate and precise way, because according to their faith humans are made by God in his own image. No exaggeration, no disproportion is allowed in the early western paintings. All the humans as well as other creatures and plants in the world have to be taken in the vivid, proportional, accurate and photographic way. This feature is obvious in the western early sculptures too. Ancient Chinese painters used paintings as an expression of their inner feelings rather than merely capturing the world in the photographic way. What they want to emphasize is not the real objects that have already existed in the natural world, but their philosophic thoughts and their life attitudes towards all the things around them.

Another feature of Chinese paintings is the commonly used blank spaces, which can not be understood by many western viewers who heard that Chinese painting's value is usually measured by it size. Chinese painters seldom use bright colors in their creation. Ink plays the dominant role in Chinese paintings. Burnt ink, thick ink, dry light ink, light ink and wet ink are called the "Five kinds of color" in Chinese painting theories. The mixing and mastering of the five kinds of color could last a lifetime. Therefore the painters leave the unmarked blank space in contrast to other inked objects on purpose to evoke the sky, water, fog or simply nothing - just a sensation of emptiness.

Because of different instruments, materials and cultural background, Chinese paintings have the uniqueness in 
techniques.

\subsection{The Uniqueness of Chinese Painting in Motifs}

The most important factors for Chinese Painting are the special motifs and the unique Chinese philosophy. The Chinese Painters are trained not only to convey the objects but also express the mood and the spirit of the subject. The Chinese also believe that the painting is the expression of the painter's knowledge and temperament. In this way, Chinese Painting becomes something much more than art.

It's easy to find something as minute as a humming bird with its fragile wings, the robust legs of the cricket or a lonely swimming shrimp in water as the chosen objects in Chinese painting. For example, the motifs of the masterpieces of Qi Baishi are quite similar: swimming shrimps, blossoming peonies or joyful catfishes. The most popular objects range from flowers, fruit and vegetables, birds, insects, animals, fish to landscapes. It's obvious that the Chinese painters enjoy the nature and they love the most humble things in the natural world. Gu Kaizhi proposed the theory of "communication of the soul" and promoted that the deciding factor of good painting was whether it "communicating the soul" (Lin, 2010). The Chinese painter finds it offensive to contemplate and draw the human figure by itself. Human beings are part of the surrounding heavens and earth. Humans, Heaven and Earth should be a unity.

The philosophy of traditional Chinese landscape painting would be summed up as "regarding Nature as the teacher outside and using the spirit or intellect as the creative source inside". Landscape paintings need to be created from the combination of the natural environment and the creative vision. "Regarding Nature as one's teacher outside" does not mean only painting the appearance of a mountain, an animal or some flowers, but also means feeling the spirit of nature. The creational process is to turn the scenery of nature into scenery of the heart, and then transfer the combination of both into paintings.

Another essential philosophy of China is the unity of Heaven, Earth and Human Beings. What the Chinese Painters are trying to express is not what meets the eye, but their attitude to the Great Nature. The Chinese painter has a profound love and admiration for nature. It is part of their culture, religious practices and their need to depend on nature to survive.

In relationship to human and animal figures, the Chinese painter utilizes the forms he finds in nature. However, their western counterparts think humans to be the most attractive motif. They want to present the human figures, body shapes, and the facial expressions in an accurate and even scientific way.

\subsection{The Uniqueness of Chinese Painting in Forms}

Many of the works in Chinese Painting take the form of painted handscrolls, which, as with Chinese text, were intended to be read from right to left. Taking advantage of the scroll's horizontal format, painters present scenes in a continuous sequence. The joy of the scroll as a mode of visual storytelling lies in the fact that the viewer can control the pace at which they proceed and move back and forth between scenes. In this way, it is a far freer experience than watching a film or a play.

Calligraphy, or writing as fine art, was revered as a visual art form long before painting. From the 12th century, during the Song dynasty, it was regarded as integral to the painter's practice; training in the five major calligraphic styles (seal, clerical, regular, running and cursive) formed part of an artist's basic education.

Inscriptions could bring a number of extra dimensions to a work. The numerous seal marks imprinted on paintings over many centuries tell the viewers much about the background, its owner, and the hidden information which can't be presented clearly from the painting itself. Seals were used by collectors to mark their ownership of paintings, even before artists began to use them as a form of signature, as the artist acquired a higher status.

Chinese paintings were fragile because of its special materials. Typically, a Chinese scroll painting would be stored rolled up in a box or hanged on the wall for a certain time. Owners would derive maximum enjoyment from rotating their paintings, which also minimized damage from sunlight, grease and dust. In the 17th century, during the height of connoisseurship, some collectors even tried to develop a formula for the rotation of paintings. Because of their fragility, many works in the show are exhibited a maximum of once every five years and some have never been seen in Europe.

\section{Chinese Paintings: Read between the "Lines"}

From the above discussion, it's quite obvious that Chinese Painting is not easy to read. To fully understand it, the 
viewers have to read between the "lines". Here "lines" can either refer to the techniques or the strokes the painters use in their arts creation, or the hidden information behind the external visual presentation. Basically, to read Chinese painting, the viewers have to read the painting with their eyes and their hearts.

The Chinese paintings bear a distinctive national identity because of its long history and its profound cultural heritage. The Chinese nationality produces something typical and unique in Chinese paintings, such as seals, inscriptions, the various style names of painters in different periods, and the classical poems, which serve as a combination of mood with the picture. In the translation process, if the information is processed in the Foreignizing Translation or Minoritizing Translation, the original style may be maintained, and Chinese paintings' unique ethnic flavor are kept fresh, but the viewers may be lost in the translation; if the information is processed in the Domesticating Translation or Domestication way, the information is expressed in the typical idiomatic way, which may easily bridge the language barriers between different nations, but something unique and exotic in Chinese painting is lost.

The painters are usually multi-talented poets and calligraphers. In the ancient times, it's quite common for people to have many different names in different periods to distinguish oneself from others: the family name is inherited from the family; the given usually is given by the parents or the grandparents; the courtesy name (or style name) is given when the child becomes a grown-up; the literary name (or pen name, sobriquet) is the way how the painter name himself. For example, Huang Kung-wang, the famous painter, (original name Lu Chien) went by the style name Tzu-chiu and sobriquets Ta-ch'ih and I-feng tao-jen. The Lu family thereupon consented to allow Huang to adopt him and carry on the Huang name. Huang exclaimed by saying "Old Man Huang has always longed for a son," which became the basis of Huang Kung-wang's style name, which translates literally as "Huang's Longing for a Son." The famous painter has a original name(原名), and he was given a style name (字) later when he reached 20, and when he painted he usually signed his literary name (号) on his final work.

The titles of Chinese paintings are the "eyes" of the works. The viewers may glance at the title and have a first impression as to what the painting is about.

Some of the titles are direct and simple, for example, Qi Baishi's work "Shrimp"(1927) vividly presents a swimming shrimp in water and his anther work "Peony" (1947), which is quite obvious from the title, is about the flower peony. Usually in these paintings the painters are trying to present the beautiful objects in nature: a few shrimps, a lotus, or a flying butterfly. The content is in accordance with the title, or in other words, the viewers may predict what they will see in the painting based on the information they get from the title.

Some of the titles may contain symbolic meanings. To fully understand such symbolic titles, the viewers have to make certain associations and connections. These symbolic paintings have basically tow layers: one is the visual image (the external image shown on the painting) and the other one is the hidden information (the internal and deep information which does not stated clearly). The visual image is just the carrier of the hidden information. The hidden information of Chinese painting is a complicated system, which includes the Chinese history, classical allusions, legends and customs. One should never interpret Chinese paintings without the cultural and social context. Otherwise, what they can see is just the external visual image. The hidden information, in which the essence and the most joyful part of "reading Chinese Painting" lies, is lost in misreading and partial reading.

For example, Qi Baishi's work "Catfish" (1937) is more than just a picture of a fish. It's true that the object in painting is a catfish, which in Chinese is called 鲶鱼.“鲶”which has the resembling pronunciation of “年”, means years and “鱼” which is similar to “余” in pronunciation, means rich or abundance. When the two Chinese characters are combined together, the hidden meaning is longevity. But when the western viewers see the title "catfish" for the first time, they will not have any cultural association like the natives do. Instead, they may start to wonder what's the real meaning of presenting a single catfish? Why did the master choose a catfish not any other fish? The master concealed his best wishes in such a clever way. The title is pale and meaningless when the cultural context and social context are deprived of. Actually, many objects in Chinese paintings are symbolic too. Insects are indicative of many values: bees (industry and hard work), butterflies (summer, fall, joy, good luck, grace and light), cicada (eternal youth and happiness), cricket (summer and courage). A pair of butterflies shows nuptial harmony, which serves as a meaningful gift to a newly wedded couple. Fruit plays a major part on New Year's and other special celebrations. They also have some symbolic meanings accumulated in generations: apple (peace), apricots and cherries (fair lady), Buddha's hand and oranges (good fortune and immortality), peaches (longevity, spring, and marriage), pears (August), persimmons (joy), plums (hope, good fortune, purity, and longevity). Vegetables like fungus (longevity, fertility, immortality) and gourds (longevity) are the popular symbolic objects too.

Another such example is Qi Baishi's "Eagle on a Pine Tree" (1940). In the painting, an eagle is sitting still on a pine 
tree, with its eyes looking into the distance. It looks like the eagle is pondering over something troublesome and painful. The careful viewers will notice the poem written on the painting, which shows that the painter was worried about the nation in the revolutionary time and he was waiting for the very one who could save the ruined nation out of wars and pain. It's very common for the painters to express their heroism and their wishes by drawing the image of an eagle. Birds used as symbols in Chinese paintings include rooster (courage, virtue, life force and warmth), crane (youth, longevity, good fortune and promotion), eagle (heroism), peacock (beauty), phoenix (peace and prosperity). A pair of birds means peace, harmony, and a happy marriage. A pair of peacocks symbolizes business prosperity.

Another interesting example of Chinese paintings is the famous "the Riverside Scene in Pure Brightness" which measures $24.8 \mathrm{~cm}$ by $528.7 \mathrm{~cm}$. This large scroll painting portrays various aspects of Kaifeng during the Song dynasty. Minutely detailed, the characters and scenes are proportional from any angle. Originally the Chinese name of the painting is 清明上河图. There are seven versions alone in the National Palace Museum, and this one by court painters of the imperial painting academy under the Ch'ien-lung Emperor (reigned 1736-1795) is one of the most famous. Each version reflects not only the painting style but also life and appearances of the period it was made. It combines the style and features of previous versions along with unique customs of the Ming and Ch'ing, such as the forms of entertainment popular at the time. The lively activities include a theatrical performance, monkey show, acrobatics, and a martial arts ring to lend a festive air to the scenery. It is a valuable source of information for late Ming and early Ch'ing life and customs. The style also reflects the influence of Western painting techniques, popular at the court then. The buildings and streets, for example, were rendered with Western-style perspective, and even some Western-influenced architecture appears. However, the dispute as to what's the real meaning of the title “清明 上河图” has never been settled.

Basically, there're three popular conclusions: some people think “清明” in the painting is the name for an ancient place near Kaifeng, Henan Province; some people argue that “清明” is the traditional festival in China, which is also called tomb sweeping day; and still others hold the opinion that “清明” is the complimentary words of the painter when he dedicated the finished painting to the first collector - the emperor Song Huizong. In the archaic sense, “清 明” refers to the peaceful and harmonious reign. All the different opinion holders have their reasons and proofs. The real and original meaning of the title still maintains a mystery in Chinese paintings. There're many different English versions of the title: those who think “清明” is the traditional festival put it as follows: "Upper River during the Qing Ming Festival", "Riverside Scene of the Qing Ming Festival", "Scroll of Pure Brightness Festival on the River", "Along the River during Ching Ming Festival", "Life Along the Bian River at the Pure Brightness Festival"; those who think “清明” is the name of the place call it “The Picture of River in Qingming”; those who think “清明” is the complimentary words translate it as "Peace Reigns over the River", or "A Peaceful and Harmonious Village along the Bian River". In The World Exposition Shanghai 2010, the digital version of"清明上河图” got the worldwide attention and it was given a very beautiful and poetic name"River of Wisdom".

\section{Conclusion}

Cultivated in Chinese history, literature and philosophy, Chinese painting has its unique motifs, forms and techniques. The painters love the lively and beautiful creatures in nature and they devoted their inner feelings and their philosophic thoughts into the paintings. To fully understand Chinese paintings, the viewers have to look beyond the visual images presented on the paper and dig out the hidden information and the inner feelings behind the external objects. This process is called "reading Chinese painting", which is very interesting, joyful, meaningful and essential in fully understanding Chinese paintings. The cultural and social associations and connections help the viewers to better comprehend the Chinese paintings through the establishment of an all-round and multi-dimensional background information system.

\section{Acknowledgements}

The present research is sponsored by Beijing Higher Education Young Elite Teacher Project (YETP1507).

\section{References}

Lin Ci. (2010). Chinese Painting: Capturing the Spirit of Nature with Brushes. Beijing: China Intercontinental Press. The Metropolitan Museum of Art. Eagle on a Pine Tree [EB/OL]. (2014-02-18). Retrieved on 2014-02-18 from 
$\mathrm{http} / /$ www.metmuseum.org/Collections/search-the-collections/49651?rpp=20\&pg=1\&ao=on\& $\mathrm{ft}=\mathrm{chinese}+$ paint ing \&who $=\mathrm{Q} i+$ Baishi\&pos $=2$

The National Palace Museum. 富春山居圖(無用師) [EB/OL]. (2012-3-22). Retrieved on 2014-02-18 from http://www.npm.gov.tw/zh-TW/Article.aspx?sNo=04000975

The National Palace Museum. 清院本清明上河圖 [EB/OL]. (2012-4-18). Retrieved on 2014-02-18 from http://www.npm.gov.tw/zh-TW/Article.aspx?sNo=04000988

The Metropolitan Museum of Art. Shrimp [EB/OL]. (2014-02-18). Retrieved on 2014-02-18 from http://www.metmuseum.org/Collections/search-the-collections/49648?rpp=20\&pg=1\&ao=on\&ft=chinese+paint ing\&who $=\mathrm{Q}+\mathrm{B}$ Baishi\&pos $=1$

The Metropolitan Museum of Art. Catfish [EB/OL]. (2014-02-18). Retrieved on 2014-02-18 from http://www.metmuseum.org/Collections/search-the-collections/49654?rpp=20\&pg=1\&ao=on\&ft=chinese+paint ing $\&$ who $=\mathrm{Q} i+$ Baishi\&pos $=3$ 